\title{
Síntese de colágeno após a implantação de telas de polipropileno em parede abdominal de ratos jovens e velhos ${ }^{1}$
}

\author{
Collagen synthesis after the implantation of polypropylene nets \\ in the abdominal wall of young and old rats
}

\author{
Maria de Lourdes Pessole Biondo-Simões ${ }^{2}$, Vanessa L. Westphal ${ }^{3}$, Josué Bruginski de Paula ${ }^{4}$, Karin Soldatelli Borsato ${ }^{5}$, \\ Lucia de Noronha ${ }^{6}$ \\ 1. Estudo realizado na Disciplina de Técnica Operatória - Metodologia da Pesquisa do Curso de Medicina da Pontifícia Universidade Católica \\ do Paraná (PUCPR) \\ 2. Professora Titular de Técnica Operatória da PUCPR, coordenadora da Disciplina de Técnica Cirúrgica e Cirurgia Experimental da \\ Universidade Federal do Paraná - TCBC-PR. \\ 3. Aluna do Programa de Iniciação Cientifica, bolsista do PIBIC-PUCPR \\ 4. Professor de Técnica Operatória da PUCPR \\ 5. Professora Titular do Laboratório de Ensaios da PUCPR \\ 6. Professora de Patologia Experimental da PUCPR.
}

\section{RESUMO}

Objetivo: Alguns autores afirmam que a síntese do colágeno em indivíduos idosos é mais lenta, outros que há diminuição da síntese de colágeno I e III e outros que é normal. O objetivo deste estudo foi reconhecer a deposição de colágeno através dos poros de tela de polipropileno, implantada em parede abdominal de ratos adultos jovens e comparar à de ratos velhos. Métodos: Utilizaram-se 10 ratos machos com idade entre 100 e 120 dias e 10 ratos com idade entre 850 e 900 dias. Sob anestesia inalatória fez-se uma incisão mediana na parede abdominal ventral e produziu-se uma falha com $4 \mathrm{~cm}^{2}$, retirando-se o plano músculo-aponevrótico, mantendo-se o plano peritoneal. Corrigiu-se a falha com malha de polipropileno fixada com pontos separados de fio 5.0, também de polipropileno e fez-se a síntese da pele. Após 30 dias fez-se a eutanásia e retirou-se a parede abdominal ventral com a prótese. Dividiu-se o retalho com o enxerto em 2 partes, uma ensaio de tração e a outra para estudo histopatológico. Coraram-se os cortes obtidos pela hematoxilina e eosina e Sirius-red. Estes foram examinados em microscópio de luz polarizada através do programa Image Plus. Resultados: O ensaio de tração não demonstrou diferença significante de resistência entre os dois grupos. Reação inflamatória agudo-crônica, com grande quantidade de células gigantes de corpo estranho, esteve presente nos dois grupos com intensidade semelhante, o mesmo acontecendo com a concentração total de colágeno ( $p=0,1440)$ e de colágeno tipo I ( $p=0,3981)$. Já a concentração de colágeno tipo III era maior nos cortes dos animais velhos ( $\mathrm{p}=0,0364)$. Conclusão: Estes resultados permitem concluir que o envelhecimento não prejudica o ganho de resistência e a deposição de colágeno, porém existe atraso da maturação tecidual.

Descritores: Cicatrização de feridas. Colágeno. Próteses. Envelhecimento.

\section{ABSTRACT}

Purpose: Some investigators have stated that collagen synthesis is slower in elderly individuals, others have reported a reduction of collagen I and III synthesis, and still others have reported normal synthesis. The objective of the present study was to determine the collagen deposition occurring through the pores of a propylene net implanted in the abdominal wall of young adult rats compared to old rats. Methods: Ten male rats aged 100 to 120 days and 10 rats aged 850 to 900 days were used. Under inhalatory anesthesia, a median incision was made in the ventral abdominal wall and a $4 \mathrm{~cm}^{2}$ gap was formed. The muscle-aponeurosis plane was removed and the peritoneal plane was maintained. The gap was corrected with a polypropylene mesh fixed with separate 5.0 polypropylene sutures and the skin margins were joined. The animals were sacrificed 30 days later and the ventral abdominal wall with the prosthesis was removed. The flap with the graft was divided into 2 parts, one for the traction assay and the other for histopathological study. The sections obtained were stained with hematoxylin-eosin and Sirius-red and examined under a polarized light microscope using the Image Plus software. Results: The traction assay did not demonstrate a significant difference in resistance between groups. An acute-chronic inflammatory reaction with large quantities of giant foreign body cells was present at similar intensity in both groups, the same being observed for total collagen concentration $(p=0.1440)$ and type I collagen concentration $(\mathrm{p}=0.3981)$. In contrast, type III collagen concentration was higher in the sections from old animals ( $\mathrm{p}=0.0364)$. Conclusion: These results permit us to conclude that aging does not impair the resistance gain or collagen deposition, although a delayed tissue maturation occurs.

Key words: Wound healing. Collagen. Mesh. Aging. 


\section{Introdução}

Os progressos da medicina têm proporcionado melhor compreensão do binômio saúde-doença, assim como os avanços tecnológicos, permitido diagnósticos mais precisos e terapêuticas mais eficientes, além da profilaxia das doenças. Como resultado a condição de saúde melhorou e a longevidade do homem se aumentou ${ }^{1}$ e cresceu a população de idosos nos hospitais ${ }^{2}$. A realização de procedimentos cirúrgicos em pacientes idosos é acompanhada da preocupação de médicos e familiares quanto às complicações. Muitos autores referem que a idade não é fator predisponente de complicações porém quando acontecem os riscos de morbi-mortalidade são maiores $^{3-7}$. Vários estudos descreveram atraso da reepitelização, resposta proliferativa dos queratinócitos diminuída além de "turnover” diminuído ${ }^{8-10}$. Quando se trata da síntese e concentração de colágeno em feridas, as descrições são muito controversas. Tan e col. ${ }^{11}$ demonstraram diminuição de colágeno tipo I em idosos. Chyun e Griminger ${ }^{12}$ descreveram diminuição do colágeno tipo I em ratos idosos e Reed e col. ${ }^{13}$ confirmaram em camundongos idosos. Ashcroft e col. ${ }^{14}$ afirmaram que em feridas de camundongos idosos existe diminuição da síntese dos colágenos III e I e Swift e col. ${ }^{15}$ relataram que a síntese de colágeno em feridas de animais idosos é mais lenta. Cristofalo e Pignolo ${ }^{16}$ mostraram, em estudo “in vitro”, que fibroblastos senescentes são incapazes de responder a estímulos mitogênicos; porém Fredland e col. ${ }^{17}$ não encontraram evidências de que a idade levasse ao declínio da secreção de colágeno pelos fibroblastos humanos. Kletsas e col. ${ }^{18}$ afirmaram que não existiam evidências de uma relação de dependência da idade no declínio da resposta de fibroblastos humanos a vários fatores de crescimento como: EGH, TNF- $\alpha$ e PDGF. Em trabalho realizado em nossa linha de estudo verificou-se que, após 21 dias da operação, as feridas peritônio-músculoaponevróticas dos animais velhos tinham menor concentração de colágeno do que as dos animais jovens ${ }^{19}$. Existe discussão quanto à síntese de colágeno e envelhecimento, contudo não se encontrou descrição da capacidade dos fibroblastos migrarem através dos poros das malhas usadas como próteses na correção de hérnias, técnica muito difundida na atualidade, nem tampouco da concentração de colágeno, em animais velhos. O objetivo deste estudo foi reconhecer a capacidade de síntese do colágeno e a maturação da cicatriz, após a implantação de malha de polipropileno na parede abdominal de ratos jovens e comparar com o mesmo procedimento em ratos velhos.

\section{Métodos}

Este estudo seguiu as normas de pesquisa com animais preconizadas pelo Colégio Brasileiro de Experimentação Animal (COBEA) e a Lei Federal 6.638. Utilizaram-se 20 ratos (Rattus norvegicus albinus, Rodentia mammalia), WistarPUCPR, machos, 10 deles com idade entre 100 e 120 dias e 10 ratos com idade entre 850 e 900 dias. Sob anestesia inalatória de éter etílico, induzida em sistema fechado e mantida em sistema aberto, fez-se a depilação da parede abdominal ventral seguida de anti-sepsia com polivinilpirrolidona-iodo. Fez-se uma incisão, com 6 cm, na pele e na tela subcutânea e em seguida demarcou-se uma falha no plano músculo-aponevrótico com $4 \mathrm{~cm}^{2}$, tendo $2 \mathrm{~cm}$ de lado. Identificou-se a cicatriz umbilical, que era usada para ponto central. A falha estava colocada atingindo a cicatriz e $1 \mathrm{~cm}$ para cima, $1 \mathrm{~cm}$ para baixo e $1 \mathrm{~cm}$ para cada lado da linha média. Retirou-se o plano músculoaponevrótico da área demarcada, procurando-se manter íntegro o plano peritoneal. Uma malha de polipropileno (Marlex®) ${ }^{\circledR}$ com $9 \mathrm{~cm}^{2}$, tendo $3 \mathrm{~cm}$ de lado foi aplicada para corrigir a falha músculo-aponevrótica. Fixou-se a malha com fio de polipropileno 5.0, usando-se 8 pontos separados e fechados com 4 semi-nós, ficando as margens da prótese sob o plano muscular. Em seguida procedeu-se à síntese da pele com fio 4.0 monofilamentar de náilon. Após a recuperação anestésica os animais retornavam às suas caixas, onde permaneceram até a data prevista para a aferição. A aferição foi realizada com 30 dias, quando os animais foram submetidos à eutanásia. Retirou-se um retalho da parede abdominal com 5 X $5 \mathrm{~cm}$, que continha a prótese. Desprezados $1 \mathrm{~cm}$ do retalho, na margem caudal e na margem cranial, restou um retalho com $3 \times 5 \mathrm{~cm}$ que dividido forneceu 2 retalhos iguais. Um serviu para a realização ensaio de tração, feito no Laboratório de Ensaios Destrutivos da PUCPR, para se conhecer a resistência da parede e o outro para estudo histopatológico. Utilizou-se a coloração da hematoxilina-eosina para reconhecimento do processo inflamatório e a técnica do Sirius-Red para a análise do conteúdo do colágeno. As leituras foram feitas em microscópio de luz polarizada acoplado a um computador, pelo programa Image-Plus 4.0. Os resultados foram submetidos à análise estatística usando-se o teste $t$ de student e estabelecendo-se pd”0,05 ou 5\% como nível para rejeição da hipótese de nulidade.

\section{Resultados}

No ensaio de tração perderam-se 2 retalhos do grupo jovem e 3 do grupo velho, por falha técnica. Embora se tenha encontrado tendência de maior resistência no grupo velho, o tratamento estatístico demonstrou que a diferença entre os dois grupos não era significante (Figura 1 e Tabela 1 ).

Reação inflamatória esteve presente em todos os cortes histológicos examinados. Era do tipo agudo-crônica, com grande quantidade de células gigantes de corpo estranho (Figura 2) e de tecido de granulação, representado por colágeno e neovascularização (Figura 3). A concentração de colágeno total, obtida pela média da leitura em cinco campos, foi semelhante nos dois grupos ( $\mathrm{p}=0,1440)$, o mesmo acontecendo com o colágeno tipo I $(\mathrm{p}=0,3981)$. O colágeno tipo III foi mais abundante no grupo velho $(\mathrm{p}=0,0364)$ (Tabela 2). Na figura 4 pode-se ver aspectos do colágeno demonstrando em verde o colágeno tipo III e em tons do amarelo ao vermelho, o colágeno tipo I. 


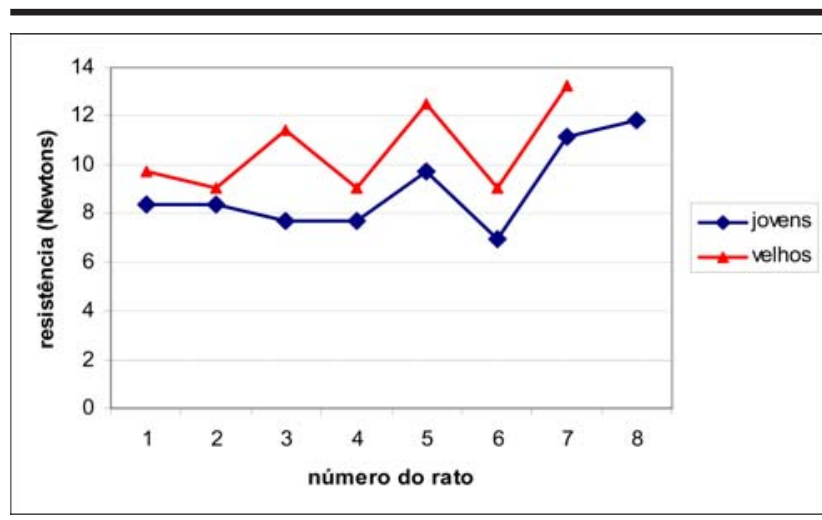

FIGURA 1 - Resistência encontrada nos dois grupos Média no grupo jovem $=8,96 \pm 1,76 \mathrm{~N}$ Média no grupo velho $=10,57 \pm 1,79 \mathrm{~N}$ Teste $\mathrm{t} \rightarrow \mathrm{p}=0,0511$

TABELA 1 - Resistência oferecida ao ensaio de tração pelos retalhos obtidos da parede dos animais jovens e velhos (Newtons)

\begin{tabular}{cll}
\hline Rato & Jovens & Velhos \\
\hline 1 & 8,348 & 9,739 \\
2 & 8,348 & 9,043 \\
3 & 7,652 & 11,390 \\
4 & 7,652 & 9,043 \\
5 & 9,739 & 12,520 \\
6 & 6,956 & 9,043 \\
7 & 11,130 & 13,220 \\
8 & 11,830 & \\
\hline Média & 8,957 & 10,571 \\
Desvio Padrão & 1,762 & 1,788 \\
\% do Desvio Padrão & 19,650 & 16,910 \\
\hline
\end{tabular}

Teste $\mathrm{t}$ de student $\mathrm{p}=0,051128$

* Perda de 2 retalhos do grupo dos jovens e de 3 do grupo dos velhos

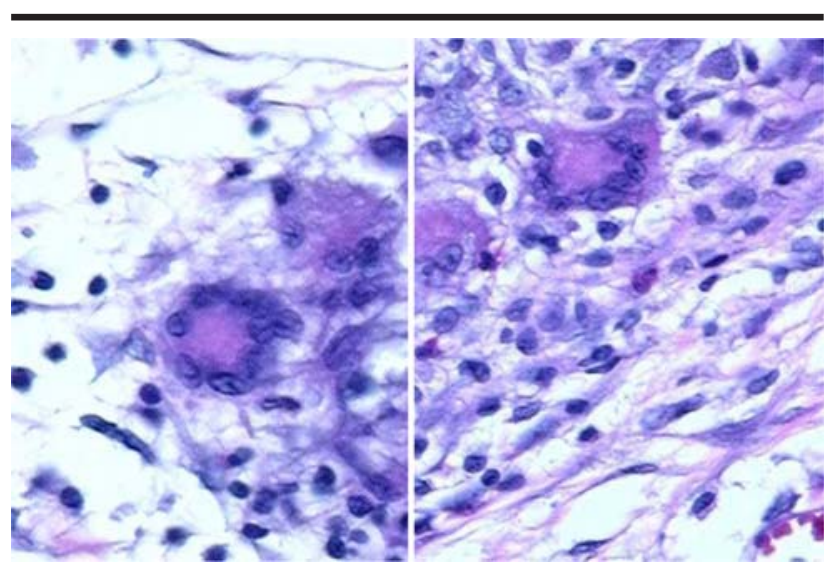

FIGURA 2 - Fotomicrografias demonstrando, à esquerda, células inflamatórias e células gigantes de corpo estranho em parede de animal jovem e à direita em parede de animal velho (HE - 400 X)

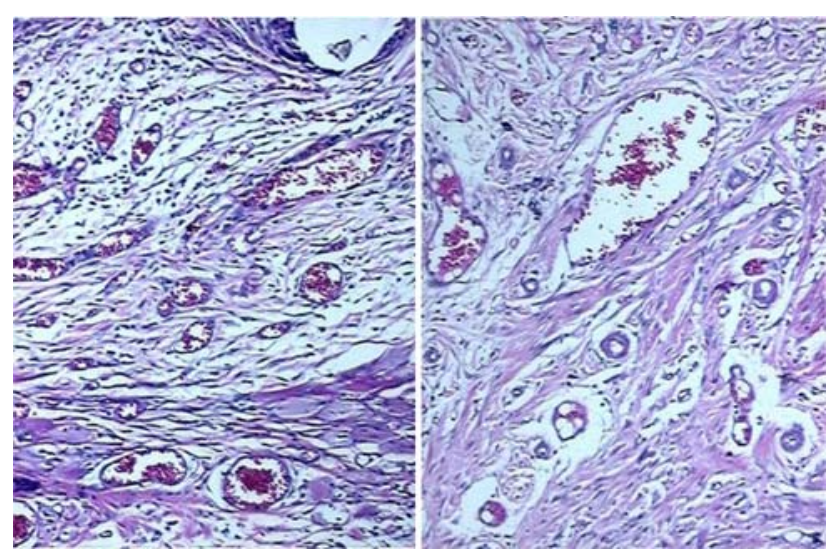

FIGURA 3 - Fotomicrografias demonstrando, à esquerda tecido de granulação em parede de animal jovem e à direita, em parede de animal velho $(\mathrm{HE}-100 \mathrm{X})$

TABELA 2 - Média da densidade, em cinco campos, do colágeno total e das frações de colágeno tipo I e tipo III nos cortes histológicos dos dois grupos (\% da área do campo examinado ocupada por colágeno)

\begin{tabular}{|c|c|c|c|c|c|c|}
\hline & \multicolumn{2}{|c|}{ Colágeno I } & \multicolumn{2}{|c|}{ Colágeno III } & \multicolumn{2}{|c|}{ Colágeno Total } \\
\hline & Jovem & Velho & Jovem & Velho & Jovem & Velho \\
\hline & 37,54 & 38,95 & 24,44 & 18,79 & 61,97 & 57,74 \\
\hline & 31,46 & 25,31 & 16,86 & 18,39 & 47,32 & 43,70 \\
\hline & 40,56 & 24,73 & 19,49 & 23,58 & 60,05 & 48,31 \\
\hline & 38,92 & 31,23 & 20,11 & 16,74 & 59,03 & 47,97 \\
\hline & 30,09 & 32,38 & 29,97 & 30,97 & 60,06 & 63,35 \\
\hline & 27,19 & 34,67 & 19,31 & 30,65 & 46,50 & 65,32 \\
\hline & 25,57 & 37,17 & 20,73 & 26,60 & 46,30 & 63,77 \\
\hline & 33,01 & 30,51 & 17,89 & 23,57 & 50,90 & 54,08 \\
\hline & 33,38 & 38,56 & 14,53 & 30,81 & 47,91 & 69,37 \\
\hline & 34,51 & $*$ & 17,11 & $*$ & 51,62 & $*$ \\
\hline Média & 33,22 & 32,61 & 20,04 & 24,45 & 53,17 & 57,07 \\
\hline DP & 4,88 & 4,97 & 4,15 & 5,65 & 6,39 & 8,51 \\
\hline$\% \mathrm{DP}$ & 14,69 & 15,24 & 20,74 & 23,10 & 12,02 & 14,91 \\
\hline
\end{tabular}

Test $\mathrm{t}$ de student

Colágeno I $\mathrm{p}=0,3981$

Colágeno III $\mathrm{p}=0,0364$

Colágeno total $\mathrm{p}=0,1440$ 


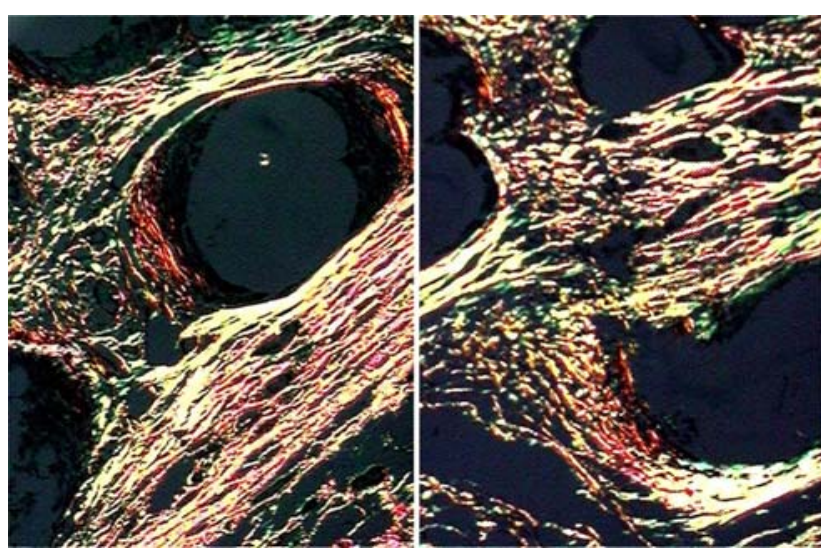

FIGURA 4 - Fotomicrografias demonstrando, à esquerda em parede de animal jovem e à direita em animal velho, a disposição do tecido colágeno ao redor dos fios da trama da prótese. ( Sirius Red - 200 X)

\section{Discussão}

Em estudo anterior, quando se estudou a densidade de colágeno nas cicatrizes de aponevroses, em ratos velhos, verificou-se que aos 14 dias não havia diferença entre jovens e velhos, porém com 21 dias as cicatrizes dos jovens tinham mais colágeno do que as dos velhos. Entretanto, a amostra estudada era pequena e isto poderia não representar a realidade ${ }^{19}$. Vários estudos encontrados na literatura, demonstram a concentração de colágeno em feridas cutâneas $^{13-15}$ entretanto, é muito importante reconhecer o comportamento da cicatriz aponevrótica e da incorporação dos implantes de próteses, pois delas depende a resistência e a integridade das paredes abdominais. Tan e col. ${ }^{11}$ afirmaram que feridas cutâneas de idosos possuem menos colágeno tipo I. Este afirmação já havia sido demonstrada experimentalmente, em ratos, por Chyum e Griminger ${ }^{12}$ e confirmada, em camundongos por Reed e col. ${ }^{13}$ e Ashcroft e col. ${ }^{14}$ demonstraram que além da diminuição colágeno tipo I havia também a diminuição do colágeno tipo III. No presente estudo verificou-se que a resistência e a presença de colágeno nas telas foi semelhante nas paredes de animais jovens e velhos, apenas a maturação foi mais lenta nos animais velhos, o que leva a pensar que os fibroblastos desempenham suas funções de forma semelhante e a supor que apenas a maturação das cicatrizes é mais lenta nos animais velhos, visto que a presença de colágeno III foi mais significante nos animais velhos. Swift e col. ${ }^{15}$ já haviam feito esta afirmativa ao estudar feridas cutâneas de animais velhos. É interessante observar que neste estudo, não se encontrou diferenças quanto à densidade de colágeno total, apenas a maior concentração de colágeno tipo III. Deve-se lembrar que este colágeno foi lido nos espaços dos orifícios das telas e os dados dos autores citados, na tela subcutânea, extratos de diferente composição e vascularização. É possível supor que fibroblastos de ratos velhos conservam sua capacidade de migrar através dos orifícios das telas e sintetizar colágeno.

\section{Conclusão}

O envelhecimento não prejudica o ganho de resistência e a deposição de colágeno entre as malhas da prótese, porém existe atraso da maturação da cicatriz, nas condições do experimento.

\section{Referências}

1. Reiss R, Deutsch AA, Nudelman I. - Surgical of donor age on epidermal growth factor processing in man. Exp Cell Res. 1993; 209:118-22.

2. Bufalari A, Ferri M, Lolli G, Fabbri C, Bisacci R. - La chirurgia generale nel paziente ottuagenario. Minerva Chir. 1996; 51(6):383-8.

3. Carlson MA. - Acute wound failure. Surg Clin North Am. 1997; 77(3):607-36.

4. Mendoza CB, Postlethwait RW, Johnson WD. - Incidence of wound disruption following operation. Arch Surg. 1970; 101(3):396-8.

5. Montesani C, De Milito R, Chiappolone S, Narilli P, D'Amato A, Ribotta G. - Critical evaluation of the anastomoses in large bowel surgery: experience gained in 533 cases. Hepatogastroenterology. 1992; 39(4):304-8.

6. Riou JP, Cohen JR, Johnson H Jr. - Factors influencing wound dehiscense. Am J Surg. 1992; 163(3):324-30.

7. Schrock TR, Deveney CW, Dunphy JE. - Factors contributing to leakage of colonic anastomoses. Ann Surg. 1973; 177(5):513-8.

8. Gilchrest BA. - In vitro assessment of keratinocytes aging. J Invest Dermatol. 1983; 81(1 Suppl):184s-9s.

9. Holt DR, Kirk SJ, Regan MC, Hurson M, Lindblad WJ, Barbul A. - Effect of age on wound healing in healthy human beings. Surgery. 1992; 112(2):293-9.

10. Morris GM, Hamlet R, Hopewell JW. - The cell kinetics of the epidermis and follicular epithelium of the rat: variations with age and body site. Cell Tissue Kinet. 1989; 22(3):213-22.

11. Tan EM, Rouda S, Hoffren J, Chen YQ, Uitto J, Li K. Extracellular matrix gene expression by human keratinocytes and fibroblasts from donors of varying ages. Trans Assoc Am Physicians. 1993; 106:168-78.

12. Chyun JH, Griminger P. - Improvement of nitrogen retention by arginine and glycine supplementation and its relation to collagen synthesis in traumatized mature and aged rats. J Nutr. 1984; 114(9):1697-704.

13. Reed MJ, Corsa A, Pendergrass W, Penn P, Sage EH, Abrass IB. - Neovascularization in aged mice: delayed angiogenesis is coincident with decreased levels of transforming growth factor beta 1 and type I collagen. Am J Pathol. 1998; 152(1):113-23.

14. Ashcroft GS, Kielty CM, Horan MA, Ferguson MW. Age-related changes in the temporal and spatial distributions of fibrillin and elastin mRNAs and proteins in acute cutaneous wounds of healthy humans. J Pathol. 1997; 183(1):80-9.

15. Swift ME, Kleimann HK, DiPietro LA. - Impared wound repair and delayed angiogenesis in aged mice. Lab Invest. 1999; 79(12):1479-93.

16. Cristofalo VJ, Pignolo RJ. - Replicative senescence of human fibroblast like cells in culture. Physiol Rev. 1993; 
73(3):617-38.

17. Freedland M, Karmiol S, Rodriguez J, Normolle D, Smith D, Garner W. - Fibroblast responses to cytokines are maintained during aging. Ann Plast Surg. 1995; 35(3):290-6.

18. Kletsas D, Pratsinis H, Zervolea I, Handris P, Sevaslidou E, Ottaviani E, Stathakos D. - Fibroblast responses to exogenous and autocrine growth factors relevant to tissue repair: the effect of aging. Ann N Y Acad Sci. 2000; 908:155-66.

19. Biondo-Simões MLB. - Os efeitos do envelhecimento na cicatrização: avaliação da parede abdominal e de anastomoses colônicas, em ratos [Tese - Professor Titular]. Curitiba (PR): PUCPR; 2001, 168p.

\section{Correspondência}

Maria de Lourdes Pessole Biondo-Simões

Conflito de interesse: nenhum

Rua Ari José Valle, 1987, Santa Felicidade

Fonte de financiamento: nenhuma

CEP 82030-000, Curitiba - Paraná

e-mail:biondo@avalon.sul.com.br

\section{Como citar este artigo:}

Biondo-Simões MLP, Westphal VL, Paula JB, Borsato KS, Noronha L. Síntese de colágeno após a implantação de telas de polipropileno em parede abdominal de ratos jovens e velhos. Acta Cir Bras. [periódico na internet] 2005 Jul-Ago;20(4). Disponível em URL: $\underline{\text { http://www.scielo.br/acb }}$

* Figuras coloridas disponíveis em http://www.scielo.br/acb

\section{ACTACIRÚRGICABRASILEIRA}

\section{QUALIS “A” nacional e QUALIS “C” internacional pela CAPES.}

\section{Indexada nas bases de dados LILACS, SciELO e MEDLINE.}

